\title{
PENGARUH MODEL PEMBELAJARAN KOOPERATIF TIPE NUMBERED HEAD TOGETHER TERHADAP HASIL BELAJAR PASSING BOLA VOLI
}

\author{
Gusti Ngurah Agus Sugianto, Dr.H. Wahjoedi, M.Pd, Ni Luh Putu Spyanawati, S.Pd, M.Pd \\ Prodi Pendidikan Jasmani, Kesehatan dan Rekreasi \\ Jurusan Pendidikan Olahraga \\ Fakultas Olahraga dan Kesehatan Universitas Pendidikan Ganesha \\ Singaraja, Bali \\ e-mail : ngurahbegok1995@gmail.com,wahjoedi@undiksha.ac.id, \\ putu.spyanawati@undiksha.ac.id
}

\begin{abstract}
ABSTRAK
Penelitian ini bertujuan untuk mengetahui pengaruh model pembelajaran kooperatif tipe Numbered Head Together terhadap hasil belajar passing bola voli. Penelitian ini adalah penelitian eksperimen sungguhan (true experimental) dengan menggunakan rancangan penelitian the randomized pretest-postest control group the same subject design. Subjek penelitian yaitu siswa kelas VIII SMP Negeri 1 Seririt Tahun Pelajaran 2018/2019 yang berjumlah 255 orang yang terdistribusi ke dalam delapan kelas yaitu kelas VIII A sampai dengan kelas VIII H. Teknik pengambilan sample menggunakan simple random sampling. Data hasil belajar dikumpulkan melalui tes objektif dan tes unjuk kerja. Analisis data menggunakan uji-t dengan taraf signifikasi 0,05 . Berdasarkan analisis data, rata-rata hasil belajar kelompok eksperimen adalah 0,71. Sedangkan rata-rata kelompok kontrol adalah 0,47. Hasil analisis data Uji-t menunjukan angka signifikasi 0,000 $(P<0,05)$. Jadi disimpulkan model pembelajaran kooperatif tipe Numbered Head Together berpengaruh signifikan terhadap hasil belajar teknik dasar passing bola voli. Disarankan kepada guru PJOK agar menerapkan model pembelajaran Numbered Head Together pada materi bola voli karena terbukti berpengaruh signifikan terhadap hasil belajar peserta didik.
\end{abstract}

Kata kunci : Kooperatif, NHT, hasil belajar, passing Bola Voli.

ABSTRACT

This study aims to determine the effect of the Numbered Head Together cooperative learning model on volleyball passing learning outcomes. This research is a true experimental study (true experimental) using the randomized pretest-posttest control group research design the same subject design. The research subjects were students of class VIII of SMP Negeri 1 Seririt in the 2018/2019 academic year, totaling 255 people distributed into eight classes, namely classes VIII A to class VIII $H$. The sampling technique used was simple random sampling. Learning outcomes data are collected through objective tests and performance tests. Data analysis using t-test with a significance level of 0.05 . Based on data analysis, the average learning outcomes of the experimental group were 0.71 . While the average control group was 0.47 . The results of the t-test data analysis showed a significance number of $0,000(P<0.05)$. So it was concluded the cooperative learning model type Numbered Head Together had a significant effect on learning outcomes of the basic technique of passing volleyball. It is recommended to PJOK teachers to apply the Numbered Head Together learning model on volleyball material because it is proven to have a significant effect on student learning outcomes.

Keywords: Cooperative, NHT, learning outcomes, volleyball passing. 


\section{PENDAHULUAN}

Salah satu cara agar dapat menciptakan manusia yang cerdas adalah melalui peningkatan hasil belajar. Untuk dapat meningkatkan hasil belajar dengan baik perlu memperhatikan faktor-faktor yang mempengaruhinya. Hasil belajar dipengaruhi faktor eksternal dan internal. Seperti dikatakan Slameto (2003:54) bahwa "faktor-faktor yang mempengaruhi hasil belajar banyak jenisnya, tetapi dapat digolongkan menjadi dua golongan saja, yaitu intern dan ekstern". Salah satu faktor ekstern yang mempengaruhi hasil belajar adalah faktor lingkungan sekitar. Hal tersebut dikarenakan semakin baik guru menerapkan model pembelajaran semakin baik pula siswa memahami materi pembelajaran, sebaliknya guru yang kurang persiapan dan penyajiannya tidak jelas menyebabkan siswa kurang memahami pelajaran dan berdampak pada hasil belajar.

Untuk meningkatkan hasil belajar siswa, perlu dilakukan peningkatan kualitas pembelajaran. Subadi (2011) menyatakan bahwa upaya meningkatkan kualitas pembelajaran sangat dipengaruhi oleh faktor siswa, alat pendukung terjadinya pembelajaran, dan lingkungan. Alat pendukung pembelajaran meliputi guru, kurikulum, sarana dan prasarana.Guru merupakan alat pendukung pembelajaran karena guru bertugas mempersiapkan dan mengelola pembelajaran. Dalam hal ini guru diharapkan dapat menyiapkan model pembelajaran dengan baik dan tepat sehingga peserta didik lebih mudah membangun pemahamannya sendiri. Hal ini menunjukkan bahwa model pembelajaran yang dipilih berpengaruh pada hasil belajar siswa. Siswa diharapkan dapat berperan penuh dalam proses pembelajaran dengan guru sebagai fasilitator.

Para pakar pendidikan telah banyak mengadakan terobosan tentang model pembelajaran yang telah diujicobakan namun sampai sekarang belum bisa dipastikan mana yang paling tepat, karena dalam proses pembelajaran sangat tergantung pada kondisi dan situasi siswa. Permasalahan tersebut harus dicarikan jalan keluarnya agar tujuan pendidikan dapat tercapai. Salah satunya dengan melakukan penelitian-penelitian guna mencari alternatif pemecahan masalah. Penelitian dapat dilakukan olah guru atau calon guru guna mencari fakta-fakta pada saat pembelajaran berlangsung, sebagai contoh melakukan observasi, mencari data untuk menunjukan letak permasalahan pada proses pembelajaran. Permasalahan ini muncul dikarenakan guru menggunakan model pembelajaran yang kurang inovatif (konvensional) yang membuat siswa kurang aktif dalam mengikuti pembelajaran, guru masih menggunakan kelompok besar sehingga guru sulit untuk mengontrol siswa, kurangnya tanggung jawab siswa di dalam pembelajaran, ditandai dengan sikap kurang antusiasnya siswa dalam menerima pelajaran PJOK khususnya pada materi teknik dasar passing bola voli. Maka dari itu peneliti akan menggunakan model pembelajaran kooperatif tipe NHT agar siswa bisa mengikuti pembelajaran yang optimal dan bisa memperbaiki hasil belajarnya. Di pembelajaran kooperatif tipe NHT setiap siswa akan memiliki tanggung jawab tersendiri.

Dari uraian di atas peneliti akan mencoba memberikan salah satu alternatif pemecahan masalah yaitu dengan menerapkan model pembelajaran kooperatif tipe NHT. Menurut Trianto (2007: 82), model pembelajaran kooperatif tipe $\mathrm{NHT}$ atau penomoran berpikir bersama merupakan jenis pembelajaran kooperatif yang dirancang untuk mempengaruhi pola interaksi siswa dan sebagai alternatif terhadap struktur kelas tradisional. Dalam pembelajaran ini siswa dibagi dalam kelompok yang beranggotakan 3-5 orang dan setiap anggota kelompok diberi nomor 1-5, kemudian guru PJOK mengajukan pertanyaan kepada siswa yang nantinya siswa berpikir bersama untuk menyatukan pendapat terhadap jawaban atas 
pertanyaan yang diberikan dan meyakinkan tiap anggota kelompoknya untuk mengetahui jawaban itu, setelah itu guru PJOK memanggil satu nomor tertentu, kemudian siswa yang nomornya sesuai mengancungkan tangannya dan mencoba untuk menjawab pertanyaan untuk seluruh kelas. Kelebihan model pembelajaran kooperatif tipe NHT adalah (1) mendorong dan mengkondisikan berkembangnya sikap dan keterampilan sosial siswa, meningkatkan hasil belajar, serta aktivitas belajar siswa, (2) lebih meningkatkan pencurahan waktu untuk tugas, (3) mengedepankan penerimaan terhadap perbedaan individu, (4) dengan waktu sedikit dapat menguasai materi secara mendalam, (5) proses belajar mengajar berlangsung aktif dari siswa, (6) mendidik siswa untuk berlatih bersosialisasi, motivasi belajar lebih tinggi, dan (7) meningkatkan kebaikan budi, kepekaan dan toleransi.

Berdasarkan uraian diatas peneliti merasa terdorong untuk mengadakan penelitian yang berjudul "Pengaruh Model Pembelajaran Kooperatif Tipe Numbered Head Together (NHT) terhadap Hasil Belajar Passing Bola Voli Pada Siswa Kelas VIII SMP Negeri 1 Seririt Tahun Pelajaran 2018/2019.

\section{METODE PENELITIAN}

Penelitian eksperimental sungguhan bertujuan untuk mengetahui kemungkinan hubungan sebab akibat dengan cara memberikan satu atau lebih perlakuan kepada satu atau lebih kelompok eksperimental, dan membandingkan dengan satu atau lebih kelompok control yang tidak diberikan perlakuan (Kanca, 2010:65). Rancangan pada penelitian ini adalah rancangan the randomized pretestposttest control group the same subjec design, penelitian yang digunakan dalam penelitian ini adalah eksperimen sesungguhnya (true experimental). "jadi cirinya adalah adanya kelompok kontrol dan sampel dipilih secara random" (Dantes, 2017: 83)
Kanca (2010:20) menyatakan "sampel adalah himpunan bagian (sebagian) populasi yang diambil secara representatif dari populasi”. Jumlah populasi kelas VIII yang terdapat di SMP Negeri 1 Seririt VIII $A$, VIII B, VIII C, VIII D, VIII E, VIII F, VIII G, VIII $\mathrm{H}$, dengan jumlah 8 kelas. Delapan kelas tersebut diundi untuk menetapkan kelas yang menjadi kelas eksperimen dan kelas kontrol. Berdasarkan hasil pengundian diperoleh sampel penelitian untuk masing-masiing perlakuan.

Dalam penelitian ini yang menjadi sampel adalah peserta didik Kelas VIII SMP Negeri 1 Seririt tahun pelajaran 2018/2019 yang terdistribusi kedalam 2 kelas yaitu: VIII C berjumlah 32 orang dan VIII $F$ berjumlah 32 orang, sehingga keseluruhan jumlah subjek penelitian adalah 64 orang. Dua kelas yang ada diundi untuk menetapkan kelas yang menjadi kelas perlakuan dan kelas kontrol.

\section{HASIL DAN PEMBAHASAN}

Penelitian ini adalah penelitian yang dilakukan pada dua kelompok, yaitu kelompok perlakuan dan kelompok kontrol. Dalam penelitian ini kelompok eksperimen diberikan perlakuan berupa model pembelajaran kooperatif tipe NHT dan pada kelompok kontrol diberikan perlakuan berupa model pembelajaran konvensional. Pembelajaran kooperatif tipe NHT menghendaki dimana peserta didik dapat saling bekerjasama, saling membantu, dan saling bahu membahu dalam sebuah kelompok kecil dengan menjalankan tugas yaitu proses pembelajaran yang inovatif, sehingga menimbulkan proses pembelajaran yang menyenangkan dan peserta didik menjadi aktif, kreatif, dan disiplin dalam mengikuti kegiatan pembelajaran. Sehingga hasil belajar peserta didik akan lebih meningkat.

Berdasarkan hasil analisis data diperoleh bahwa terdapat perbedaan hasil belajar teknik dasar passing bola voli antara peserta didik yang dibelajarkan dengan model pembelajaran kooperatif tipe NHT dengan peserta didik yang dibelajarkan 
dengan model pembelajaran konvensional, ini berarti model pembelajaran kooperatif tipe NHT berpengaruh signifikan terhadap hasil belajar teknik dasar passing bola voli pada peserta didik. Hasil belajar peserta didik yang lebih baik dengan menggunakan model pembelajaran NHT juga dikuatkan oleh peneliti sebelumnya diantaranya yaitu (1) Tri Aditya Pratama (2017) menemukan bahwa pembelajaran dengan menggunakan model pembelajaran kooperatif tipe NHT memberikan pengaruh yang signifikan terhadap hasil belajar passing bola voli pada siswa kelas VIII SMP 3 Singraja dengan nilai $t_{\text {hitung }} 2,488>t_{\text {tabel }} 1,997$ dengan taraf signifikan 0,05. (2) Gede Dedy Suardika Atmaja (2018) dalam penelitiannya menyatakan bahwa terdapat perbedaan yang signifikan hasil belajar bola basket antara peserta didik yang mengikuti model pembelajaran NHT dan peserta didik yangmengikuti model pembelajaran konvensional (Rata-rata nilai yang didapat pada kelompok eksperimen 0,352, sedangkan kelompok kontrol 0,267) 0,352>0,267. (3) Wayan Andi Suandika (2018) menemukan bahwa pembelajaran dengan menggunakan model pembelajaran kooperatif tipe NHT memberikan pengaruh yang signifikan terhadap hasil belajar passing bola voli. Jadi dapat disimpulkan bahwa model pembelajaran kooperatif tipe NHT berpengaruh sangat signifikan terhadap hasil belajar passing bola voli. Hasil uji normalitas sebaran data bahwa di dapatkan hasil signifikan kelompok eksperimen sig 0,103>0,05 dan kelompok Kontrol sig 0,200>0,05 dengan demikian semua sebaran data berdistribusi normal. Data yang dianalisis adalah data Gain Skor menggunakan SPSS 16.0 for Windows.

Tabel1. Data Hasil Belajar Teknik Dasar Passing Bola Voli

\begin{tabular}{lcc}
\hline Variabel & Kelompok Eksperimen & Kelompok Kontrol \\
\hline Banyak Peserta didik & 32 orang & 32 orang \\
\hline Rata - Rata Pretest & 69.06 & 57.96 \\
\hline Rata - Rata Posttest & 91.15 & 78.68 \\
\hline Rata - Rata Gain Skor & 0.71 & 0.47 \\
\hline
\end{tabular}

Berdasarkan tabel tentang hasil belajar materi teknik dasar passing bola voli kelompok eksperimen yang berjumlah 32 orang diperoleh rata-rata nilai pretest sebesar 69,06 dan rata-rata nilai posttest sebesar 91,15 sedangkan kelompok kontrol yang berjumlah 32 orang diperoleh rata-rata nilai pretest sebesar 57,96 dan rata-rata nilai posttest sebesar 78,68. Rata-rata gain score yang didapatkan pada masing-masing kelompok adalah pada kelompok eksperimen sebesar 0,71 sedangkan kelompok kontrol sebesar 0,47.

Tabel 2.Tests of Normality

\begin{tabular}{|c|c|c|c|c|}
\hline & & Kolmc & orov & nirnov $^{a}$ \\
\hline KIS & & Statistic & $\mathrm{Df}$ & Sig. \\
\hline GainScore & Eksperimen & .147 & 32 & .078 \\
\hline & $\begin{array}{l}\text { Kontr } \\
\text { ol }\end{array}$ & .151 & 32 & .063 \\
\hline
\end{tabular}

Uji homogenitas varians dilakukan dengan pengelompokan berdasarkan model pembelajaran, yaitu model pembelajaran kooperatif tipe Numbered Head Together
(NHT) dengan model pembelajaran konvensional. Uji homogenitas varians antar kelompok dilakukan dengan bantuan SPSS 16.00 for Windows dengan menggunakan 
Levene's Test Of Equality Error Variance. Hipotesis statistik yang diuji dalam pengujian homogenitas adalah sebagai berikut.

$H_{0} \quad$ : variansi pada setiap kelompok adalah sama (homogen)

$H_{a}$ : variansi pada setiap kelompok tidak sama (tidak homogen)
Dengan kriteria pengujian yang digunakan adalah terima $H_{0}$ jika nilai $p>$ 0,05 dimana data memiliki varians yang sama apabila angka signifikansi yang dihasilkan lebih dari 0,05. Rangkuman hasil perhitungan homogenitas data menggunakan SPSS 16.00 for Windows dapat dilihat pada Tabel 3.

Tabel 3.Test of Homogeneity of Variances

GainScore

\begin{tabular}{l|ccc|}
\hline Levene Statistic & $\mathrm{df1}$ & $\mathrm{df2}$ & Sig. \\
\hline .015 & 1 & 62 & 0.903 \\
\hline
\end{tabular}

Berdasarkan Tabel 3, hasil uji Levene's menunjukkan bahwa untuk hasil belajar teknik dasar passing bola voli peserta didik taraf signifikansi 0,00<0,05. Dapat disimpulkan bahwa variansi pada setiap kelompok adalah tidak sama (tidak homogen).

Hipotesis penelitian yang telah dikemukakan dalam kajian pustaka menyatakan bahwa terdapat perbedaan hasil belajar teknik dasar passing bola voli pada peserta didik yang dibelajarkan menggunakan model pembelajaran kooperatif tipe NHT dengan peserta didik yang dibelajarkan menggunakan model pembelajaran konvensional. Pengujian hipotesis menggunakan uji $t$ dengan bantuan SPSS 16.00 for Windows. Oleh karena variansi tidak homogen maka dipilih uji non-prametric (uji Mann-Whitney $U$ ) dengan bantuan SPSS 16.00for windows. Data yang dianalisis adalah data Gain score. Hasil analisis dengan uji MannWhitney $U$ disajikan pada Tabel 4 berikut ini.

Tabel 4.Independent Samples Test

\begin{tabular}{|c|c|c|c|c|c|c|c|c|c|c|}
\hline & & \multicolumn{3}{|c|}{$\begin{array}{l}\text { Levene's } \\
\text { Test for } \\
\text { Equality of } \\
\text { Variances }\end{array}$} & \multicolumn{6}{|c|}{ t-test for Equality of Means } \\
\hline & & \multirow[t]{2}{*}{$\mathrm{F}$} & \multirow[t]{2}{*}{ Sig. } & \multirow[t]{2}{*}{$\mathrm{T}$} & \multirow[t]{2}{*}{ Df } & \multirow{2}{*}{$\begin{array}{l}\text { Sig } \\
\dot{(2-} \\
\text { tailed } \\
\quad)\end{array}$} & \multirow[t]{2}{*}{$\begin{array}{c}\text { Mean } \\
\text { Differen } \\
\text { ce }\end{array}$} & \multirow[t]{2}{*}{$\begin{array}{c}\text { Std. } \\
\text { Error } \\
\text { Differe } \\
\text { n ce }\end{array}$} & \multicolumn{2}{|c|}{$\begin{array}{c}95 \% \\
\text { Confidence } \\
\text { Interval of the } \\
\text { Difference } \\
\end{array}$} \\
\hline & & & & & & & & & Lower & $\begin{array}{l}\text { Uppe } \\
r\end{array}$ \\
\hline \multirow{2}{*}{$\begin{array}{l}\text { Gain } \\
\text { Score }\end{array}$} & $\begin{array}{c}\text { Equal } \\
\text { variances } \\
\text { assumed } \\
\end{array}$ & \multirow[t]{2}{*}{.015} & .903 & 6.186 & 62 & .000 & .20312 & .03284 & .13748 & .26877 \\
\hline & $\begin{array}{c}\text { Equal } \\
\text { variances } \\
\text { not } \\
\text { assumed }\end{array}$ & & & 6.186 & 61.994 & .000 & .20312 & .03212 & .137448 & .26877 \\
\hline
\end{tabular}


Berdasarkan Tabel 4. diperoleh nilai signifikansinya $=0,000$. Hasil ini dijadikan dasar dalam mengambil keputusan. Adapun keputusan yang diambil adalah tolak $H_{o}$ dan terima $H_{a}$. Hasil ini menyatakan bahwa terdapat perbedaan hasil belajar teknik dasar passing bola voli antara peserta didik yang dibelajarkan menggunakan model pembelajaran kooperatif tipe NHT dengan peserta didik yang dibelajarkan menggunakan model pembelajaran konvensional. Oleh karena rata-rata skor pada kelompok eksperimen $(0,71)$ lebih besar daripada rata-rata skor kelompok kontrol $(0,47)$ maka disimpulkan bahwa hasil belajar pada peserta didik yang dibelajarkan menggunakan model pembelajaran kooperatif tipe NHT lebih signifikan

dari pada peserta didik yang dibelajarkan menggunakan model pembelajaran konvensional.

Berdasarkan hasil penelitian diperoleh bahwa terdapat perbedaan hasil belajar teknik dasar passing bola voli antara peserta didik yang dibelajarkan dengan model pembelajaran kooperatif tipe NHT dengan peserta didik yang dibelajarkan dengan model pembelajaran konvensional, ini berarti model pembelajaran kooperatif tipe NHT berpengaruh terhadap hasil belajar teknik dasar passing bola voli (passing atas dan passing bawah) peserta didik.

\section{SIMPULAN DAN SARAN}

Berdasarkan hasil analisis data dan pembahasan dapat disimpulkan bahwa model pembelajaran kooperatif tipe NHT berpengaruh signifikan terhadap peningkatan hasil belajar teknik dasar passing bola voli pada peserta didik kelas VIII SMP Negeri 1 Seririt tahun pelajaran 2018/2019.

Berdasarkan hasil analis data dan pembahasan, maka dapat diajukan beberapa saran untuk proses pembelajaran dan penelitian lebih lanjut sebagai berikut :
1. Bagi guru PJOK, model pembelajaran kooperatif tipe NHT dapat dijadikan salah satu alternatif pembelajaran yang dapat diterapkan di kelas.

2. Diharapkan kepada peserta didik peserta didik yang dijadikan sampel penelitian selanjutnya lebih memperhatikan dan memahami pembelajaran yang diberikan, agar dapat menambah paradigma maupun wawasan pengetahuan khususunya dalam pembelajaran materi teknik dasar passing bola voli, maupun pada pembelajaran yang lain.

3. Bagi sekolah agar dijadikan pedoman dalam pembelajaran PJOK khususnya pada materi pembelajaran bola voli.

4. Bagi peneliti lain yang akan mengadakan penelitian dapat menggunakan model pembelajaran kooperatif tipe NHT.

\section{DAFTAR PUSTAKA}

Kanca, I Nyoman. 2010. Metodologi Penelitian Pengajaran Pendidikan Jasmanidan Olahraga. Singaraja : Universitas Pendidikan Ganesha.

Trianto. 2007. Model-model Pembelajaran Inovatif. Jakarta: Perpustakaan Nasional.

Tri Aditya Pratama, I Pt Darmayasa, Ni Md Sri Dewi Lestari (2017). Pengaruh Model Pembelajaran Kooperatif Tipe Nht Terhadap Hasil Belajar Teknik Dasar Passing Bola Basket Pada Siswa Kelas X Sma Negeri 2 Banjar Tahun Pelajaran 2016/2017. https://ejournal.undiksha.ac.id/index.php/JJ P/article/view/11263/7193 (diakses pada kamis 2 Juli 2019). 
Slameto. 2003. Belajar dan Faktor-faktor yang Mempengaruhinya. Jakarta: Rineka Cipta.

Subadi, Tjipto. 2011. PTK (Penelitan Tindakan Kelas) Berbasis Lesson Study. Surakarta: Muhammadiyah University Press.

Gede Dedy Suardika Atmaja, I Wayan Rai, Kadek Yogi Parta Lesmana (2018). Pengaruh Model Pembelajaran Kooperatif Tipe Nht Terhadap Hasil Belajar Teknik Dasar Passing Bola Voli.

https://ejournal.undiksha.ac.id/index. php/JJP/article/view/13078/8262. (diakses pada kamis 2 Juli 2019).

Wayan Andi Suandika, I Putu Panca Adi, Ni Putu Dwi Sucita Dartini (2018). Pengaruh Model Pembelajaran Kooperatif Tipe Nht Terhadap Hasil Belajar Passing Bola Voli. https://ejournal.undiksha.ac.id/index.p hp/JJP/article/view/11221/7169 (diakses pada 2 Juli 2019).

Kanca, I Nyoman. 2010. Metodologi Penelitian Pengajaran Pendidikan Jasmanidan Olahraga. Singaraja : Universitas Pendidikan Ganesha. 